\title{
Heat Transfer Analysis in Cooling System of Hydropower's Generator
}

\author{
Abdollah Khalesi Doost*, Reza Majlessi \\ Engineering Faculty, Islamic Azad University, Semnan Branch, Semnan, Iran \\ Email: ab.khalesi@yahoo.com, Majlessi_reza@yahoo.com
}

Received 2 March 2015; accepted 15 March 2015; published 16 March 2015

Copyright @ 2015 by authors and Scientific Research Publishing Inc.

This work is licensed under the Creative Commons Attribution International License (CC BY). http://creativecommons.org/licenses/by/4.0/

(c) (1) Open Access

\begin{abstract}
Cooling process of power plant generator is handled via air-cooled radiators in which the cooling water is supplied from lake with its water temperature varies from season to season. In this study, the effect of temperature fluctuations of cooling water entering the cooling system has been examined via analysis of energy (NTU method) and exergy. The exergy analysis has been done by definition of efficiency coefficient for exergy of cooling media (water) and heating media (air). Besides, the effect of changing the cooling water temperature and flow rate entering the radiators on the cooling system performance has been studied. The results revealed the generator cooling system performance level held sufficient till the temperature of inlet water was kept under $293 \mathrm{k}$ $\left(20^{\circ} \mathrm{C}\right)$. On one hand, when the temperature of cooling water at the inlet rises to $12^{\circ} \mathrm{C}$, the rate of heat exchange at radiators falls up to $34.3 \%$. On the other hand, by water temperature passing the $12^{\circ} \mathrm{C}$ limit, the efficiency of cooling media exergy falls to $78 \%$ leading to efficiency rise in radiators' heating media exergy level to $61 \%$. According to the results of this study, changing flow rate of cooling media up to $\mathbf{4 0 \%}$ gives rise to the efficiency coefficient of radiators' cooling media exergy level to about $\mathbf{1 8 . 7 \%}$. While it does not affect the efficiency level of energy at radiators, the flow rate rise of cooling media may not be considered as a way to give rise to efficiency level of radiators.
\end{abstract}

\section{Keywords}

Cooling of Generator, Air Cooler, Energy Efficiency, Exergy Analyses, Hydropower

\section{Introduction}

Since the economic growth, along with industrial development, depends on various factors such as energy and its optional exploitation, dealing with energy and management of energy consumption has a great importance.

\footnotetext{
${ }^{*}$ Corresponding author.
} 
Due to increasing need for system development of power generators, optimizing such systems sufficiently appears to be essential. In order to analyze and optimize energy systems, numerous methods have been raised and one of which is exergy analysis. An energy-exergy analysis for a power plant generator has been conducted. Both the first and second laws of thermodynamics are employed to take into account the quantity and quality of energy. From engineering point of view, energy has different kinds of qualities (in this case: usefulness) which are related to system efficiency. In exergy analysis, when the first and second rules of thermodynamics are used synchronically and the environment has been defined as the reference state, it would be clear that in which moment and how the quality of energy reduces and how this reduction could be prevented.

At first, the energy was modeled by Rostad at United States (1975). Then, by 1986, this technique was used at Sweden and during next years it has been propagated through many of countries. In order to increase the performance quality and improve thermal productivity of heat exchangers, energy and exergy analysis could be used. Dinser and Rosen (2007) found in their studies that energy and exergy analysis was an effective method which simultaneously used the mass and energy conservation equations along with the second rule of thermodynamics to design and analyze the HVAC systems [1]. This method also can be used as a tool for quantitating the system irreversibility. The irreversibility importance would be raised when its decrease led to system optimization thermodynamically. Haseli et al. (2008) [2] reached to the most suitable and optimal temperature for shell and tube heat exchangers considering exergy. Also, Wu et al. (2007) [3] investigated the efficiency of exergy transfer for heat exchangers at limited loss of pressure. In this study, the effect of exergy transfer used concept of specific exergy of flow when heat exchanger operated at temperature of lower or higher than the environment examined. Hence, energy and exergy analysis can be helpful for process engineers and analyzers sufficiently in order to give rise to productivity and decrease the loss of energy which economically is quite remarkable. Ujiie et al. in 2006 used computational fluid dynamics for hydro-generator cooling system [4]. Also Shlemmer et al. investigated about transient heat transfer in synchronous generators by numerical methods [5]. Ales Hribernik et al. in 2011 investigated about hydro-generator's cooling system [6]. In this study, heat transfer, productivity, and heat removal quantity of radiator and the efficiency coefficient of exergy at hot and cold fluids flowing in the radiators of DEZ power plant generator, on the basis of the temperature exchange of inlet cold fluid along with change in fluid flow rate, are examined and analyzed as a procedure in order to improve the working conditions of radiators.

\section{Cooling System of Generator}

Hydropower plant of DEZ dam is one of the oldest and most important Iran's hydropower plants which contains $8 \mathrm{rpm}$ units of $65 \mathrm{MW}$ leads to $520 \mathrm{MW}$ of total capacity. Among others, generator unit is the most important part of a hydropower plant whose task is to change the mechanical energy produced by water flow imposing rotation of turbine blades into electrical form of energy. Total loss in generator is made of 3 separated losses including fluid friction, copper, and iron which finally turned into heat. Thermal losses of DEZ generator at maximum load caused by losses mentioned above are equal to $1140 \mathrm{~kW}$ [7]. Owing to the fact that generator's temperature will not exceed the limit; there are obligatory cooling systems for all generators deployed in power plants. In DEZ power plant every generator equipped with 6 radiators located in the stator hub which is classified as an isolated environment. Figure 1 shows the locations of the radiators.

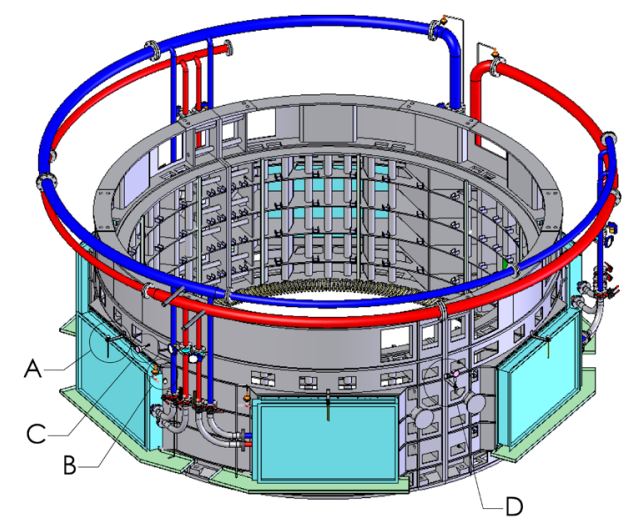

Figure 1. Schematic figure of installed radiators on stator hub of Dez power plant's generator. 
In radiators, hot fluid is warmed air flow of the generator circulated by radial fan installed on generator's rotor located in an isolated environment. Because of hydropower unit fixed rpm, the air flow rate is fixed too. Cold fluid in the radiators formed by cold water entered from lake of the DEZ dam to the cooling system. Lake level of the DEZ dam changes between 290 - 352 m measured from high sea level yearly which is affected directly on water temperature entering the cooling system. In this way, the lower the lake level, the higher the radiators-entering fluid temperature [8]. This is caused by the fact that lower layers of lake water content are not as much high due to the lack of sunlight and low pressure. Accordingly, considering the data recorded by the production and exploitation company of DEZ dam \& power plant, the temperature of radiator's inlet changes from $15^{\circ} \mathrm{C}$ to $27^{\circ} \mathrm{C}[9]$.

Other properties of the fluids flowing into the radiators are provided in Table 1.

\section{Governing Equations Used to Modeling the Generator's Radiators}

\subsection{Modeling Assumptions}

In energy \& exergy analysis of the radiators, the following assumptions have been made:

1) Steady state process.

2) The heat exchanging process in the radiators is done at an isolated and sealed environment and the process is only happened to fluids mentioned earlier.

3) The physical properties of the hot and cold fluids are considered at average temperature.

4) The analysis has been done regarding heat transfer and friction of the fluid flow.

\subsection{Energy Analysis of the Radiator}

In order to analyzing the radiator's energy, $\varepsilon$-NTU method is used in which the following parameters taken into account: The Thermal capacity rate of heat exchanger.

In radiators of generator, the ratio of heat capacity equals the heat capacity of minimum fluid (air) to that of maximum fluid (water).

$$
C=\frac{(\dot{m} c p)_{\min }}{(\dot{m} c p)_{\max }}
$$

\section{Number of Heat Transfer Units (NTU)}

According to the following equation, NTU are dependent on the general coefficient of heat transfer, the area of heat transfer and the heat capacity of minimum fluid. Therefore the analysis of energy and the efficiency of energy of radiators can be examined against the changes of the parameter of NTU.

$$
N=\frac{U \cdot A}{C_{\min }}
$$

The Effectiveness Factor or the Output of Heat Exchanger [7]

It equals the ratio of real heat transfer to the maximum transfer of permitted heat (ideal one)

$$
\varepsilon=\frac{q}{q_{\max }}=\frac{(\dot{m} c p)\left(T_{c o}-T_{c i}\right)}{(\dot{m} c p)\left(T_{h i}-T_{c i}\right)}
$$

It was supposed in radiators that

$$
q_{h}=q_{c}=q
$$

Table 1. The fluids in the radiators of the generator of Dez power plant.

\begin{tabular}{cccc}
\hline Fluid type & Fluid & Inlet temperature & Passing direction \\
Being cooled fluid & air & $63^{\circ} \mathrm{C}$ & Out of the tubes of heat exchanger \\
Cooling fluid & water & $15^{\circ} \mathrm{C}-28^{\circ} \mathrm{C}$ & Into the tubes of heat exchanger \\
\hline
\end{tabular}


And there is

$$
\begin{gathered}
q_{h}=C_{\text {min }}\left(T-T_{c i}\right) \\
q_{c}=\varepsilon \cdot C_{\text {min }}\left(T_{h i}-T_{c i}\right)
\end{gathered}
$$

Then according to the form of cross flow and the flow of two unmixed fluids for radiators generator of Dez power plant,

$$
\varepsilon=1-\exp \left[\frac{\exp (-n c n)-1}{c n}\right], \quad n=N^{-0.22}
$$

where $N$ stands for the number of thermal transfer units [10].

\subsection{Efficiency Analysis of Exergy}

The efficiency or the effectiveness factor of energy $\varepsilon_{e}$ is shown as the following equation.

$$
\varepsilon_{e}=\frac{\text { the rate of real energy transfer of fluid (cold or hot) }}{\text { the maximum rate of the possible energy of fluid(coldd or hot) }}
$$

The efficiency of energy transfer is a method with which the amount of energy transfer is acquired easily if the inlet or outlet temperatures of heat exchanger are known.

If the definition of specific thermo physical energy is considered, then

$$
e=h-h_{\infty}-T_{\infty}\left(S-S_{\infty}\right)
$$

According to $e=f(T, P)$ and using mathematical dimension of thermodynamically ratios, energy changes are attained.

If the friction of fluid flow is overlooked when the heat exchanger works in a temperature more than that of environment then [11]:

$$
\Delta E=\dot{m} C_{p}\left(T_{0}-T_{i}-T_{\infty} \ln \frac{T_{0}}{T_{i}}\right)
$$

When the heat exchanger works in a temperature less than of environment, heat transfer and exergy transfers are in opposite directions and then [12]:

$$
\Delta E=\dot{m} C_{p}\left[T_{\infty} \ln \frac{T_{0}}{T_{i}}-\left(T_{0}-T_{i}\right)\right]
$$

There is a condition in radiators of generator of Dez power plant which are illustrated in heat transfer diagram of Figure 2.

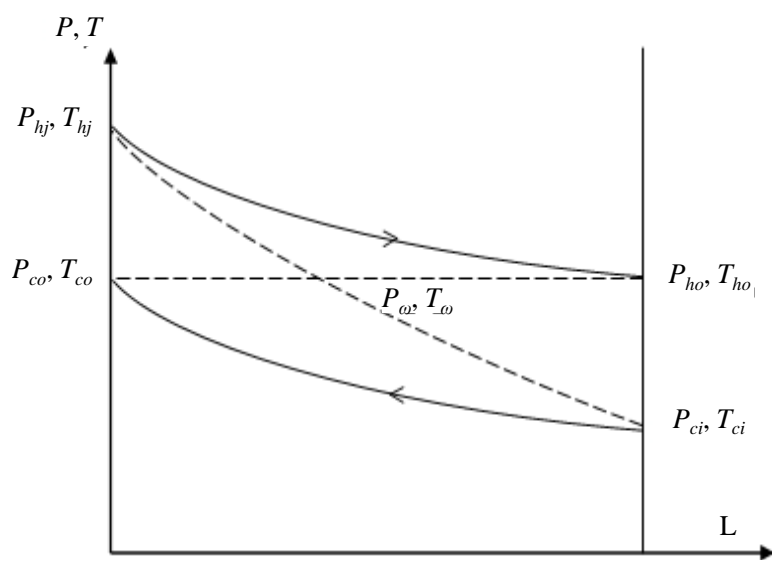

Figure 2. Heat transfer diagram for generator's heat exchangers. 
As it can be seen in Figure 2, the temperatures of cold and hot fluids are less and more than the temperature of environment respectively.

The maximum changes of possible exergy are also changes to occur when the temperature of outlet cold fluid $\left(T_{c o}\right)$ and that of inlet hot fluid $_{(\mathrm{Thi})}$ are the same in the ideal state of heat transfer. In this state some part of diagram depicts the maximum changes of exergy are less than the temperature of environment and some part illustrates those of exergy are more than the temperature of environment. According to Equations (10) and (11) and using Equation (8) for the radiators of generator of Dez power plant, then

$$
\varepsilon_{e, c}=\frac{T_{\infty} \ln \frac{T_{c o}}{T_{c i}}-\left(T_{c o}-T_{c i}\right)}{T_{\infty} \ln \frac{T_{\infty}}{T_{c i}}-\left(T_{\infty}-T_{c i}\right)+\left(T_{h i}-T_{\infty}\right)-T_{\infty} \ln \frac{T_{h i}}{T_{\infty}}}
$$

If the capacity rate of heat exchanger $(c)$ and the effectiveness factor of heat exchanger $(\varepsilon)$ are used and parameters $C_{0}, C_{1}$ and $C_{2}$ are defined as:

$$
C_{0}=\frac{T_{\infty}}{T_{h i}}, \quad C_{1}=\frac{T_{c i}}{T_{h i}}, \quad C_{2}=\frac{T_{\infty}}{T_{c i}}
$$

The efficiency of exergy of radiators cold fluid can be written according to inlet temperatures as:

$$
\varepsilon_{e, C}=\frac{C_{0} \ln \left[\varepsilon C \frac{\left(1-C_{1}\right)}{C_{1}}+1\right]-\varepsilon C\left(1-C_{1}\right)}{C_{0}\left[\ln C_{0}+\ln C_{2}-2\right]+\left(1+C_{1}\right)}
$$

And in some way for the exergy of hot fluid (air), there is:

$$
\varepsilon_{e, h}=\frac{C_{0} \ln C_{0}+C_{0} \ln \frac{C_{0}}{\varepsilon\left(1-C_{1}\right)}-2 C_{0}}{C_{0}\left[\ln C_{0}+\ln C_{2}-2\right]+\left(1+C_{1}\right)}
$$

\section{Results}

Since the temperature point of cold water entering the radiators is due to alternatively changes during different seasons of the year, and by assuming the lowest and highest local temperature of the year as lower and upper specified limit, respectively, besides by considering the dry weather and short coming of water in local area, four temperature points are selected in order to investigate thermal changes mentioned above.

$$
T_{1}=289 \mathrm{k} \quad T_{2}=293 \mathrm{k} \quad T_{3}=297 \mathrm{k} \quad T_{4}=301 \mathrm{k}
$$

Figure 3(a) represents variations in effectivity factor of heat exchanger in relation to the NTU in different temperatures of inlet cold water. As it can be seen in the figure, changes in water temperature do not affect the effectivity factor. But, increasing the NTU will give a rise to this factor. In order to show the effect of water flow rate entering the radiator, the thermal capacity which is 0.259 for DEZ radiators currently are used. Regarding fixed flow rate of hot air versus changing flow rate of cold water around $30 \%$ to $40 \%$, so there is no need to replace water pumps. The effect of the cold water flow rate fluctuation represented in Figure 3(b) in form of effectivity factor proportion to NTU at temperature of inlet water of $289 \mathrm{k}$ for various thermal capacity rates of heat exchanger. By the way, it reveals that as the cooling water flow rate increase, it has a trivial rising effect on effectivity factor.

Figure 4(a) illustrates the variations of exchanged heat (Q) against NTU at different temperatures of water flow entering the radiators. Obviously, the water flow point of temperature ascended while fixed $\mathrm{N}$ heat removal fell. In Figure 4(b), changes of exchanger heat showed in proportion to the NTU at different thermal capacity rates of the heat exchanger. As it can be seen in the Figure 5(a) graph, flow rate variations of the cooling water at the radiator's entrance do not have any specific effect on heat transfer rate while $\mathrm{N}$ is fixed.

Variation of exergy efficiency of the cooling water flowing at the radiator's entrance $\varepsilon_{e c}$ is depicted versus $\mathrm{N}$ at different temperatures of the inlet flow of water in Figure 5(b). As it rises from the figure, the efficiency of water flow exergy decreases by rising flow rate or descending thermal capacity rate of heat exchanger. 


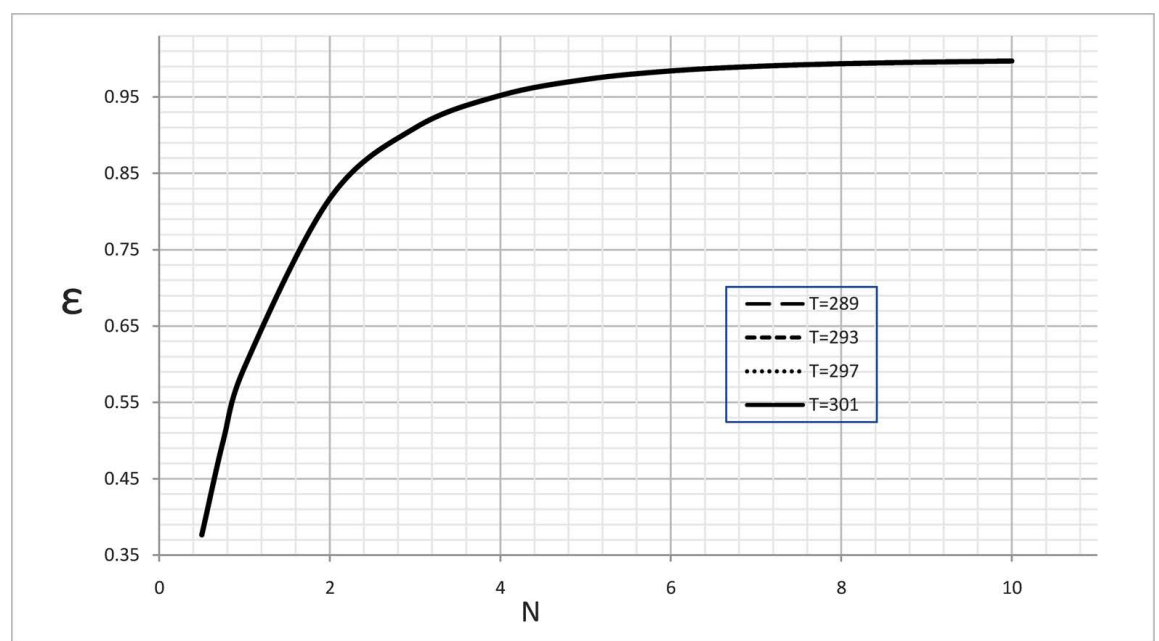

(a)

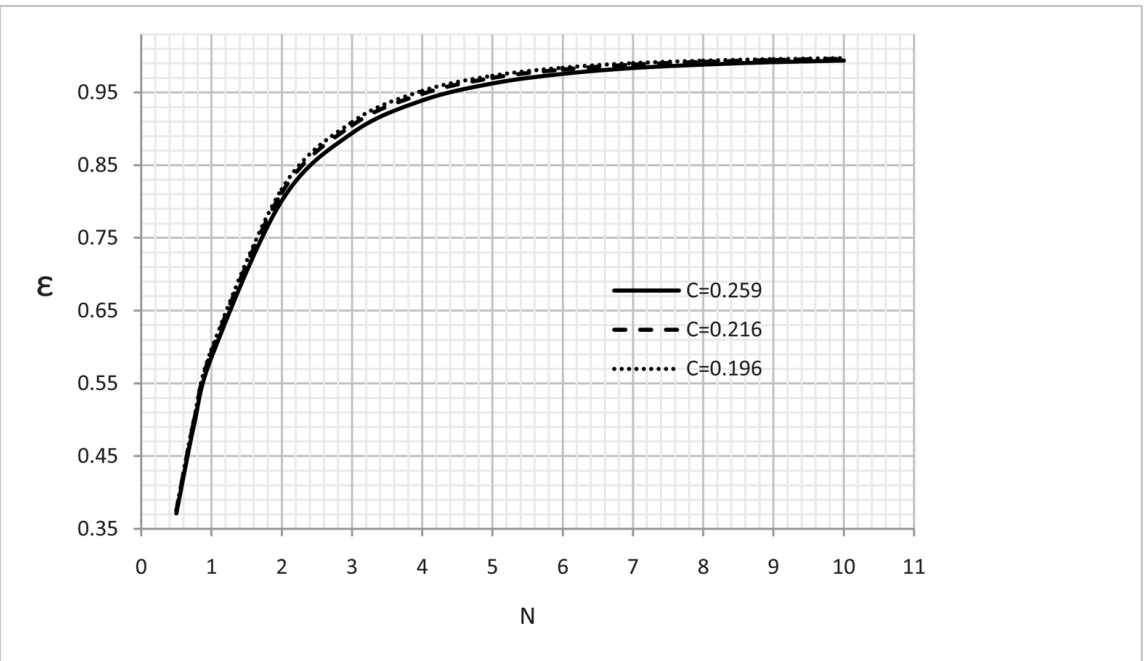

(b)

Figure 3. The changes of the effectiveness factor of radiator in proportion to the number of thermal transfer units. (a) the changes in various temperatures of inlet cold water; (b) the changes of different capacity rates of thermal exchanger.

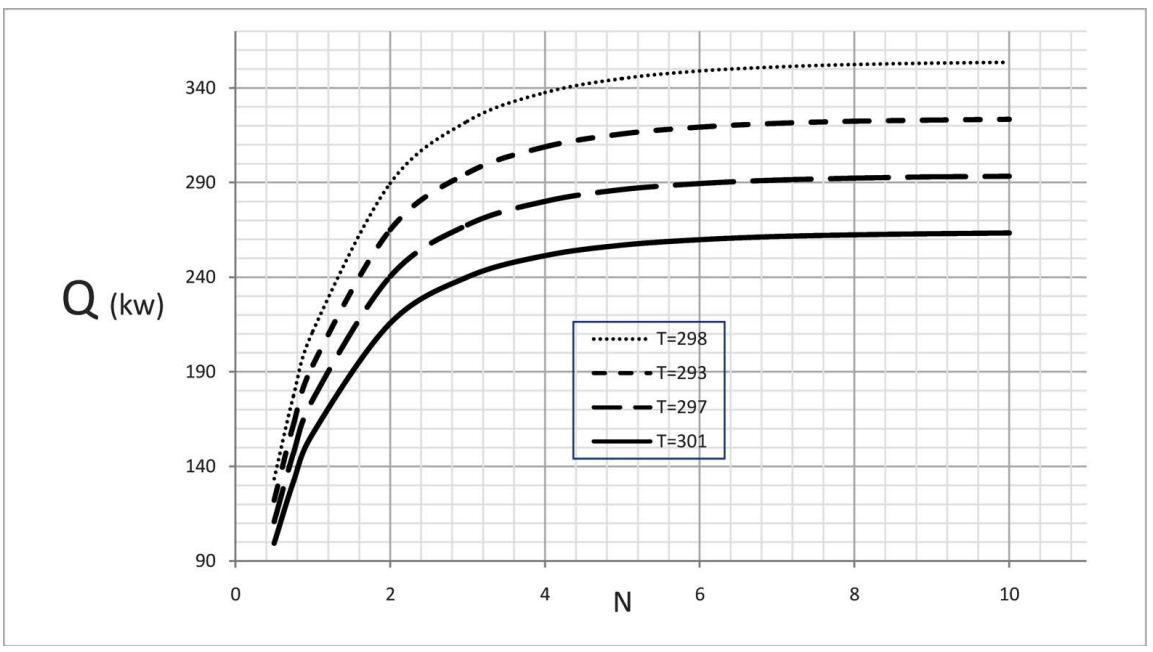

(a) 


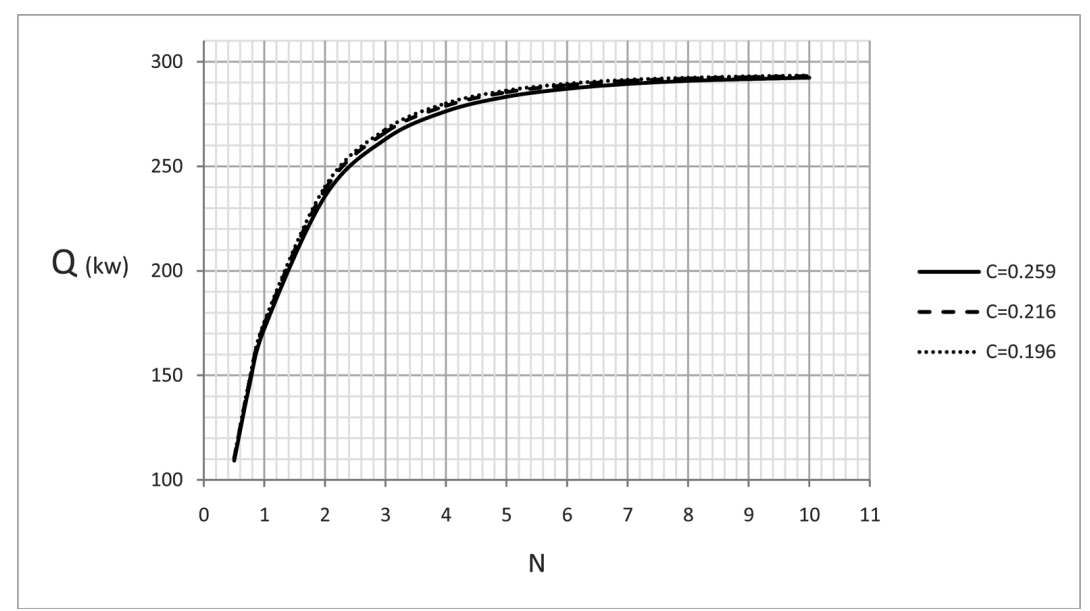

(b)

Figure 4. The changes of the quantity of heat transfer $(\mathrm{Q})$ in proportion to the number of heat thermal units $(\mathrm{N})$. (a) the changes in different temperatures of inlet cold water; (b) the changes in different capacity rates of heat exchanger.

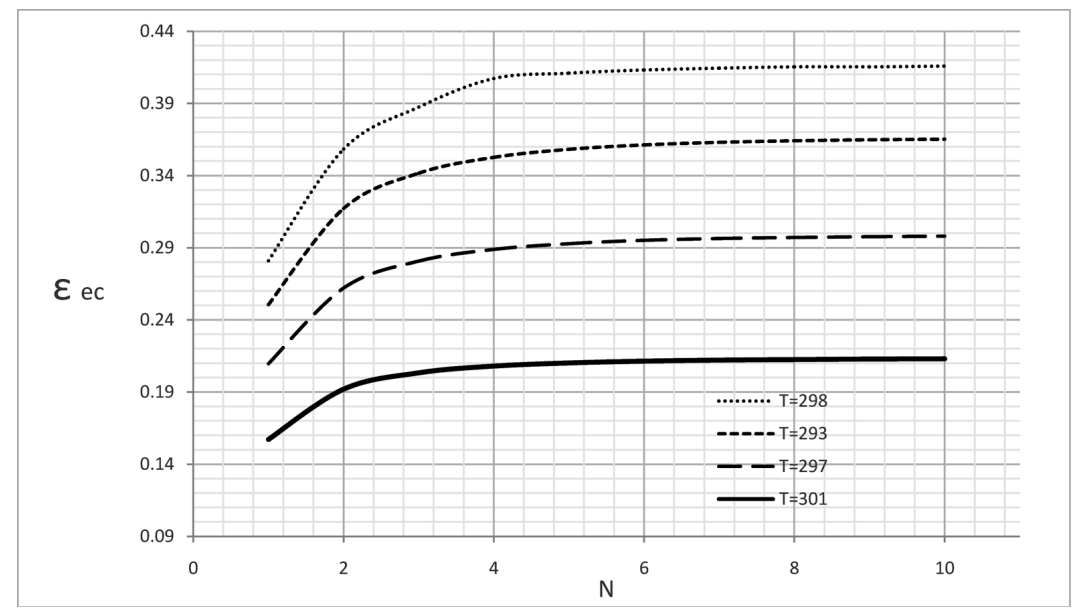

(a)

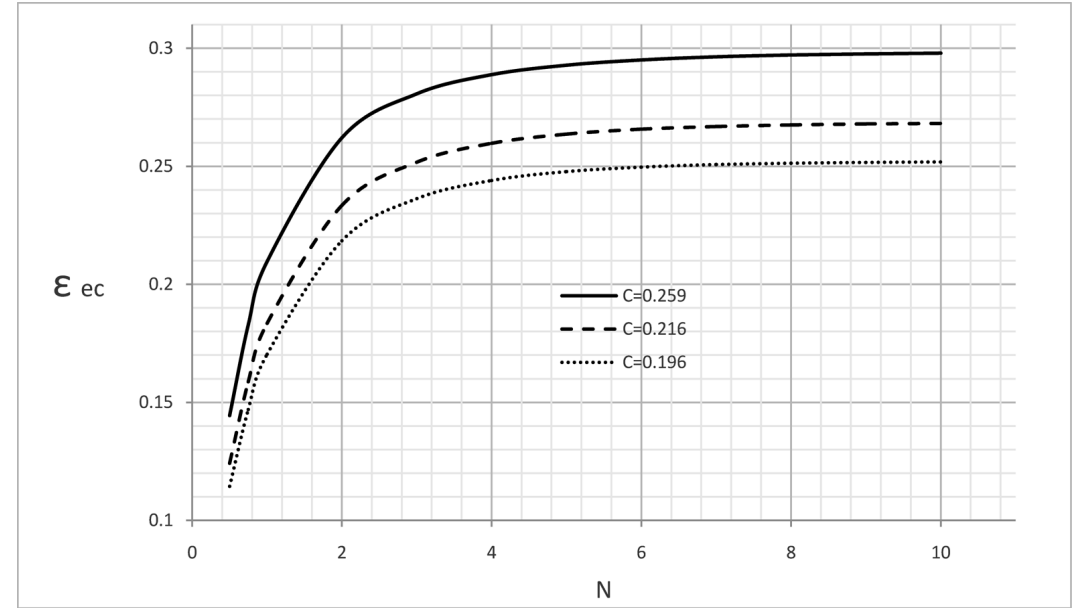

(b)

Figure 5. The changes of efficiency coefficient of cold fluid exergy of radiator in proportion to the number of thermal transfer units. (a) the changes in different temperatures of inlet cold watery; (b) the changes in different capacity rates of heat exchanger. 


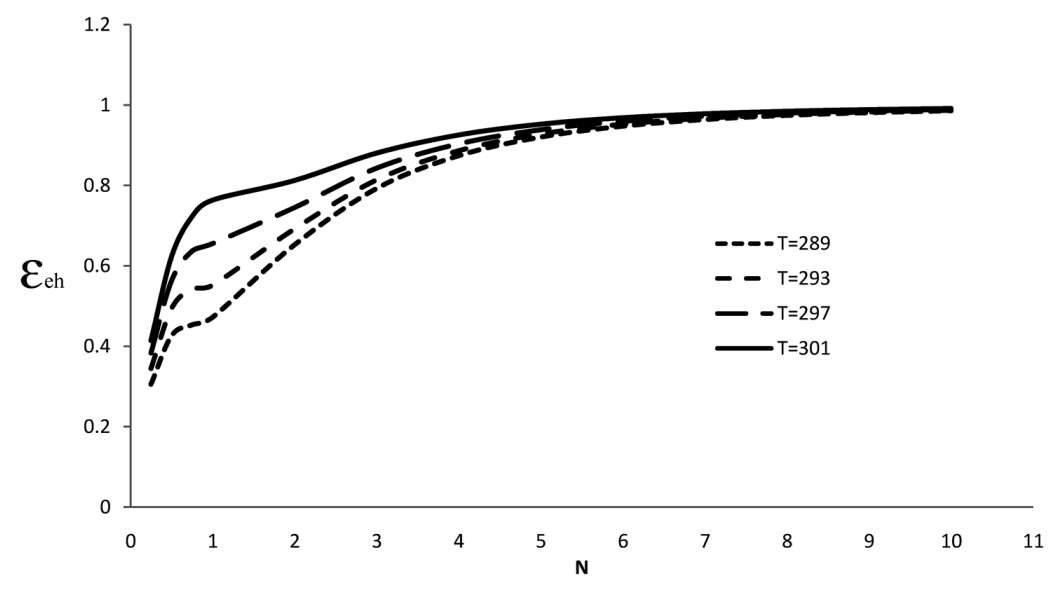

(a)

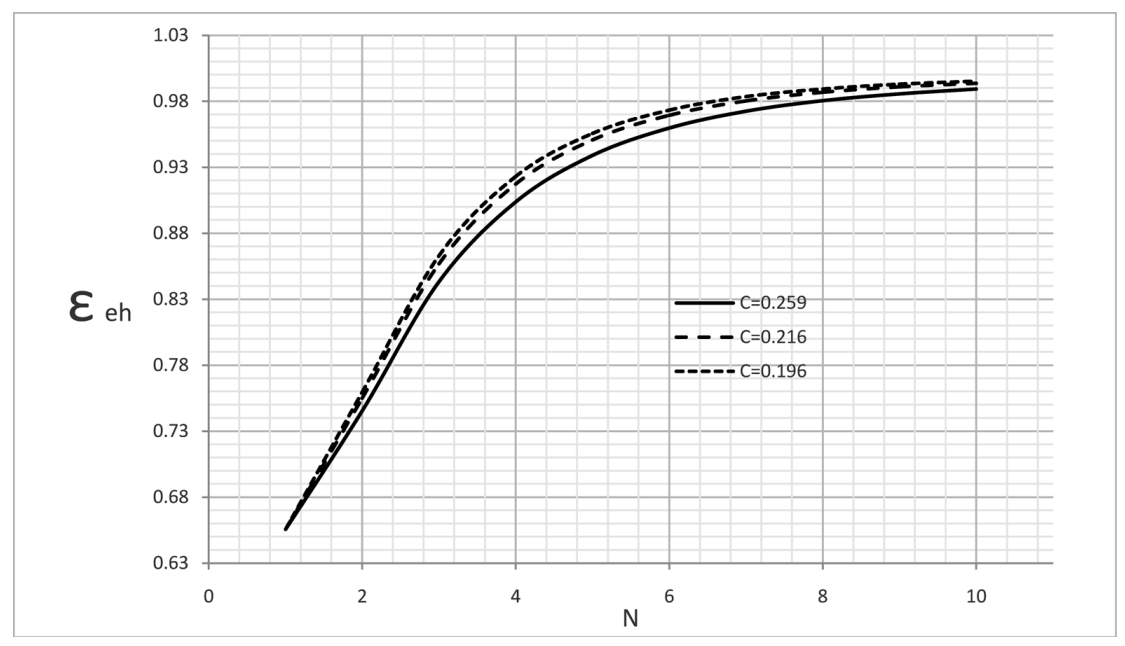

(b)

Figure 6. The changes of efficiency coefficient of hot fluid exergy of radiator in proportion to NTU. (a) the changes in different temperatures of inlet cold water; (b) the changes in different capacity rates of heat exchanger.

Figure 6(a) reveals that the exergy efficiency coefficient of the hot air $\varepsilon_{e h}$ has a rise when the temperature of cooling water flow at the inlet steps is up at fixed NTU. Besides, Figure 6(b) shows the fact that exergy efficiency of the hot air flow will not affected by increasing in flow rate of entering cold water in the radiator.

\section{Conclusion}

In case of incompressible fluid flows, like water, the heat transfer rate is high. Hence, the point of temperature at these fluids can be shown as a determinant factor in heat removal process at the time of entering heat exchanger. Therefore, the higher the inlet fluid temperature is, the lower the heat removability of the fluid is, and vice versa. After this, heat removability may not be affected by fluid flow rate mainly because of the fact that increasing fluid flow at the inlet can lead to rising the temperature point of the fluid at the heat exchanger's outlet which steps upper than previous state results in difference between inlet and outlet points of temperatures and increasing effect of inlet flow fades out. The radiator installed in the DEZ power plant's generator has an NTU of one at which heat removal of the radiator rises from $215.7 \mathrm{~kW}$ at $301 \mathrm{k}$ to $289.7 \mathrm{~kW}$ at $289 \mathrm{k}$. Accordingly, when the temperature of cooling water at the inlet rises to $12^{\circ} \mathrm{C}$, the rate of heat exchange at radiators falls up to $34.3 \%$. Also, since every generator contains six radiators and each of them must be able to transfer at least $190 \mathrm{~kW}$ of heat energy in order to chill out the generator, only each radiator which has water flow of $293 \mathrm{k}$ at the inlet would be able to transfer the thermal energy. But it cannot keep going at temperature points higher than mentioned above which is prevailed in local area by the autumn changes that caused by low level condition of the 
DEZ dam lake making operator decreasing unit load in order to prevent generator damage. The results attained in this study revealed that changing in flow rate of inlet water up to $40 \%$ of nominal value may not be made up for the decrease in radiator's heat removal. The exergy analysis of radiators examined using exergy efficiency coefficient defined as the ratio of exchanged energy between two hot and cold media to the maximum exchangeable content of exergy in the radiator. As far as cooling media concerned, increase in temperature point of entering water flow to the radiator leads to fall in efficiency coefficient of fluid exergy. In this way, it can be concluded that the higher the temperature point at the inlet, the higher the efficiency coefficient of exergy is. This relation comes from dependence of heat transfer mechanism at incompressible media on the temperature point of inlet fluid flow. Besides, at NTU = 1, the effectivity factor of cooling flow descended around 78\% when the water flow temperature point changed from $289 \mathrm{k}$ to $301 \mathrm{k}$ beside changes because of rising in water flow rate. In this condition, the efficiency coefficient of exergy may also reduce.

\section{References}

[1] Dinser, I., Rosen, M.A. (2007) Exergy: Energy, Environment and Sustainable Development. Elsevier, Oxford.

[2] Haseli, Y., Dincer, I. and Naterer, G.F. (2008) Optimum Temperatures in a Shell and Tube Condenser with Respect to Exergy. International Journal of Heat and Mass Transfer, 51, 2462-2470. http://dx.doi.org/10.1016/j.ijheatmasstransfer.2007.08.006

[3] Wu, S.-Y., Yuan, X.-F. Li, Y.-R. and Xiao, L. (2007) Exergy Transfer Effectiveness on Heat Exchanger for Finite Pressure Drop. Energy, 32, 2110-2120. http://dx.doi.org/10.1016/j.energy.2007.04.010

[4] Ujiie, R., Arlitt, R. and Etoh, H. (2006) Application of Computational Fluid Dynamics (CFD) on Ventilation-Cooling Optimization of Electrical Machines. Review Energy Technologies Generation, Transmission and Distribution of Electric and Thermal Energy, Contents 4, 17-22.

[5] Shlemmer, E., Schoenauer, J., Farnleitner, E. and Mueller, F. (2004) Transient Electromagnetic and Coolant Flow Investigation of Synchronous Generators Using Numerical Approaches. Proceedings of International Conference on Electrical Machines, ICEM, Cracow, 5-8 September 2004.

[6] Hribernik, A. and Fike, M. (2011) Investigating the Malfunction of a Hydro-Generator's Cooling System. 15th International Research/Expert Conference Trends in the Development of Machinery and Associated Technology, Bosnia and Herzegovina, 12-18 September 2011.

[7] Siemens Company (1971) Operation and Maintenance Instructions, R-34. AC Generator and Appurtenances, Khuzestan Water and Power Authority DEZ Project.

[8] Madadi, H. and Najmin, A. (2009) Survey on Thermal Stratification of Dez Dam Reservoir Using the Model CE-QUAL. 2nd Conference Exhibition of Environment Engineering, Tehran.

[9] Production and Exploitation Company of Dez Dam Power Plant, Exploition and Resistance Unit (2012) Thermal Stratification Information of Dez Lake.

[10] Incropera, F.P. and De Wite, D.P. (2002) An Introduction to Heat Transfer. 4th Edition, Johan Wily\& Sons, Hoboken.

[11] Hamid, A. (2011) Heat Exchangers (Principles, Design, Function). University of Tehran Press, Tehran , 656 p.

[12] Holman, J.P. (2008) Heat Transfer. 9th Edition, John Wiley, Hoboken. 


\section{Signs}

$C$ : the capacity ratio of heat exchanger.

$M$ : mass flow rate $(\mathrm{kg} / \mathrm{s})$.

$c_{p}$ : specific heat in fixed pressure $(\mathrm{kj} / \mathrm{kg} \cdot \mathrm{k})$.

$U$ : the coefficient of heat transfer $\left(\mathrm{w} / \mathrm{m}^{2} \mathrm{c}\right)$.

$A$ : the level of heat exchange $\left(\mathrm{m}^{2}\right)$.

$N$ : the number of heat transfer.

$Q$ : the rate of heat transfer (w).

$T$ : temperature $k$.

$\varepsilon$ : the effectiveness factor of heat exchanger.

$\varepsilon_{e}$ : the efficiency of exergy.

$E$ : the heat flow exergy $(\mathrm{kj} / \mathrm{kg})$.

$H$ : enthalpy $(\mathrm{j} / \mathrm{kg})$.

$S$ : entropy $(\mathrm{j} / \mathrm{kg} \cdot \mathrm{k})$.

$\Delta E$ : changes of exergy.

$P$ : pressure (pa).

$Q$ : heat burden $(\mathrm{kw})$.

${ }^{\circ} \mathrm{C}$ : degrees centigrade.

Footnotes:

$c$ : cold fluids.

$h$ : hot fluids.

$i$ inlet.

$o$ : outlet. 